\title{
MEMULAI USAHA DARI RUMAH DENGAN MODAL KECIL
}

\author{
Maghfiroh Yanuarti, Reza Octovian, Hendra Winarsa, Catur Galuh, \\ Panca Galuh
}

Universitas Pamulang

Email: dosen01431@unpam.ac.id

\begin{abstract}
This community service took the object of research, namely the Indonesian Army Kizinubika Unit (Persit Organization) in Raya Gunung Kapur RT05 / 03 Cogreg Parung. The purpose of this activity is so that we can develop our full potential. To assist Persit Members in starting a business independently even with a small midal. And determine what steps should be taken to plan a business. This activity includes how to start a business even with a small amount of capital because the amount of capital is relative depending on the ability of each and the knowledge gained can still be applied properly. From the results of the counseling, it was concluded that during the process Persit members were very enthusiastic about participating in community service activities held by Pamulang University lecturers, which could be seen from the responses of active participants, paying attention to the speakers and presenters and even getting carried away with the theme Starting a business from home with capital small.
\end{abstract}

Keywords: Home Business, Small Capital.

\begin{abstract}
Abstrak
Pengabdian Kepada Masyarakat ini mengambil objek penelitian yaitu Kesatuan Kizinubika TNI AD (Organisasi Persit) di Raya Gunung Kapur RT05/03 Cogreg Parung. Tujuan dari kegiatan ini adalah agar kita dapat mengembangkan potensi diri secara maksimal. Untuk membantu Anggota Persit dalam Memulai usaha secara mandiri walaupun dengan midal kecil. Dan menentukan langkah apa yang harus di tempuh untuk merencanakan usaha. Kegiatan ini meliputi bagaimana memulai usaha walaupun dengan modal kecil karena besarannya modal bersifat relatif tergantung kemampuan masing-masing dan ilmu yang di dapatkan tetap dapat di terapkan dengan baik. Dari hasil penyuluhan disimpulkan bahwa selama proses tersebut para Anggota Persit sangat antusias mengikuti kegiatan pengabdian masyarakat yang diadakan oleh dosen Universitas Pamulang yang bisa dilihat dari respon para peserta yang aktif, memperhatikan para narasumber dan pemateri bahkan sampai terbawa suasana dengan tema Memulai usaha dari rumah dengan modal kecil.
\end{abstract}

Kata Kunci: Usaha Dari Rumah, Modal Kecil. 


\section{A. PENDAHULUAN}

Saat ini banyak orang memilih membuka usaha sebagai cara untuk memenuhi kebutuhan hidup sehari-hari, baik yang sudah memiliki pekerjaan utama maupun bagi mereka yang belum memiliki pekerjaan. Bidang bisnis yang bisa dikerjakan dapat menyesuaikan dengan kebutuhan pasar saat itu ataupun dengan skill dan hobi yang dimiliki. Untuk membuka usaha, sebenarnya tak perlu langsung membuka usaha yang besar dan dengan modal yang besar pula. Berbisnis bisa dimulai dengan usaha skala kecil. Usaha dengan skala kecil yang di maksud di sini adalah usaha yang di bangun dengan investasi dana yang nilainya kecil. Tentunya, jumlah dana yang di maksud di sini setiap orang memiliki ukurannya masing-masing. Namun mungkin banyak orang yang sedikit meragukan. Sasaran yang ingin di capai melalui program ini adalah agar para peserta lebih mempunyai motivasi untuk memulai usaha, Jangan mudah putus asa, dengan usaha dan kerja keras maka hasil yang di terima juga akan maksimal. Walaupun dengan modal yang kecil kita berharap peserta dapat mengembangkan usaha tersebut maka diperlukan bekal keterampilan, pendidikan dan rasa percaya diri (motivasi) bahwa peserta dan dapat bersaing dengan usaha lainnya.

\section{B. METODE PELAKSANAAN KEGIATAN}

Metode kegiatan yang digunakan adalah kita mendatangi Kesatuan Kizinubika TNI AD (Organisasi Persit) di Raya Gunung Kapur RT 05/03 Cogreg Parung dan akan memberikan pelatihan di sana pada tanggal 4-6 Februari 2019. Pelatihan ini bertujuan agar para peserta mengetahui betapa pentingnya memahami dunia usaha untuk meningkatkan taraf hidup untuk menyongsong masa depan yang lebih baik. Kegiatan ini meliputi bagaimana memulai usaha walaupun dengan modal kecil karena besarannya modal bersifat relatif tergantung kemampuan masing-masing dan ilmu yang di dapatkan tetap dapat di terapkan dengan baik.

Persiapan yang dilakukan adalah segala hal yang terkait dengan materi, bahan dan alat sesuai dengan tema secara baik. Hasil persiapan tersebut dimaksudkan agar materi tersampaikan dengan dan mudah dimengerti serta dipahami oleh para anggota Persit Kartika Chandra Kirana Ranting 17 Kizinubika.

Persiapan Komponen dan Perlengkapan Dalam melakukan penyuluhan yang dibutuhkan adalah sebagai berikut:

1. LCD

2. Infokus

3. Contoh video (film pendek) yang menunjukan proses Perkembangan Anak dan Motivasi ibu dalam menghadapinya.

4. Gambar-gambar untuk memotivasi pengembangan dan rasa percaya diri.

\section{HASIL DAN PEMBAHASAN}

Kegiatan awal yang dilakukan yaitu berkoordinasi dengan Pengurus Persit yang ada di Daerah kawasan Parung, Kabupaten Bogor. Setelah melakukan diskusi untuk mencari kesepakatan kemudian TIM PKM melakukan koordinasi observasi TNI AD Parung atas kesediaan untuk pengadaan PKM kepada Anggota Persit Kizinubika. Tim PKM memilih karena Salah Satu anggota Kelompok merupakan Anggota Persit tersebut disana dan memudahkan Tim PKM untuk kerkoordinasi mengenai PKM tersebut. Selain itu Tim PKM memilih Organisasi Persit dengan didasarkan pada kemudahan untuk mobilasi kelokasi PKM tersebut. 
Penyuluhan untuk memotivasi Anggota Persit Kizinubika cukup lancar dan peserta dapat mengikutinya dengan baik karena di latar belakangi militer semua berjalan dengan tertib dan lancar.

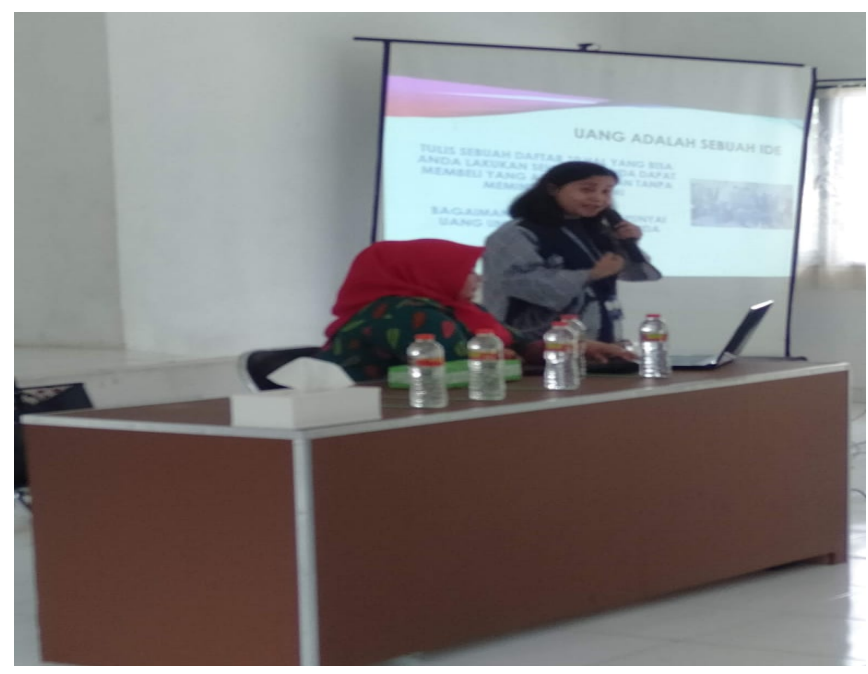

\section{Gambar 1. Pemberian Materi Oleh Tim PKM}

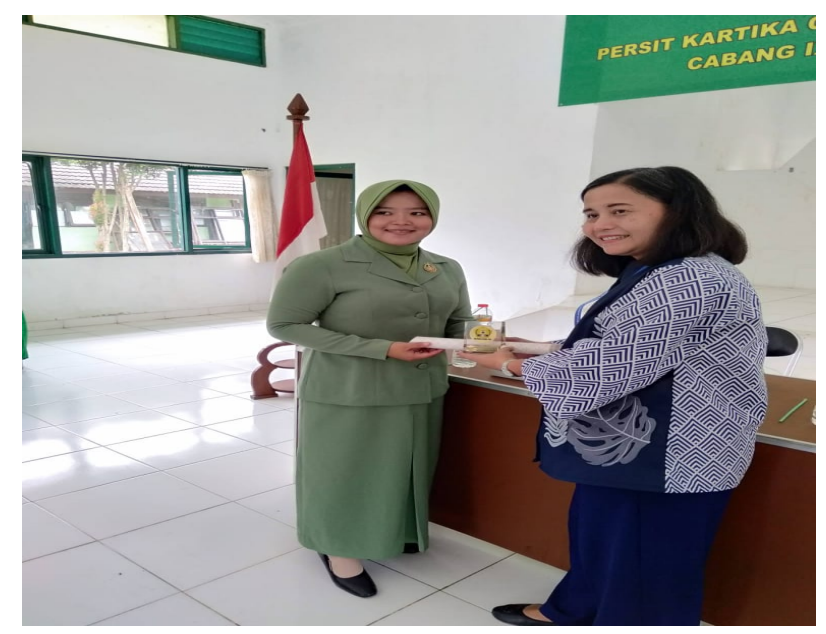

Gambar 2. Penyerahan Plakat Oleh Tim PKM

\section{KESIMPULAN DAN SARAN}

\section{Kesimpulan}

Dari hasil penyuluhan disimpulkan bahwa selama proses tersebut para Anggota Persit sangat antusias mengikuti kegiatan pengabdian masyarakat yang diadakan oleh dosen Universitas Pamulang yang bisa dilihat dari respon para peserta yang aktif, memperhatikan para narasumber dan pemateri bahkan sampai terbawa suasana dengan tema Memulai usaha dari rumah dengan modal kecil. 


\section{Saran}

Dalam laporan kegiatan ini mungkin banyak kekurangan yang ada, untuk itu kami berharap masukan dan kritikan dalam rangka perbaikan untuk kegiatan-kegiatan pengabdian masyarakat di masa yang akan datang. Semoga kegiatan pengabdian masyarakat ini dapat bermanfaat bagi masyarakat sekitar lingkungan Universitas Pamulang

\section{DAFTAR PUSTAKA}

Aidil Amin Effendy., et all. (2020). Implementasi Kewirausahaan Dan Koperasi Di Sekolah Pada Smk Mulia Buana, Parung Panjang - Kab. Bogor. DEDIKASI PKM. Vol. 1. No. 2.

Angga Juanda., et all. (2020). Menumbuhkan Rasa Gotong Royong Dan Interaksi Sosial Di Kelurahan Pondok Jaya Kota Tangerang Selatan. DEDIKASI PKM. Vol. 1. No. 2.

Dumilah, R., Sunarto A., Ahyani., Solihin, D., dan Maulida H. (2020). Pelatihan Pemanfaatan Media Sosial Untuk Promosi Usaha Atau Bisnis Bagi Siswa. DEDIKASI PKM. Vol. 1. No. 1.

Finatariani, E., Setianingsih., Anisa., Zenabia, T., dan Abdurachman, T. A. (2020). Pengelolaan Keuangan Keluarga Dan Pengenalan Dasar-Dasar Investasi Menuju Keluarga Mandiri Bagi Ibu-Ibu Majelis Taklim Al Auladiyah, Tangerang Selatan. DEDIKASI PKM. Vol. 1. No. 2.

Purwanti, Andhani D., Simangunsong. R.R., Nelsi, M., dan Yunanti, S. (2020). Membangun Mental Wirausaha Untuk Meningkatkan Taraf Hidup Masyarakat Rt 006 Rw $10 \mathrm{Kp}$ Cimuncang Destasikmalaya Karangnunggal Kabupaten Propinsi Jawa Barat. DEDIKASI PKM. Vol. 1. No. 2. 